\title{
НЕТЕРМИЧЕСКОЕ ВОЗДЕЙСТВИЕ УЛЬТРАКОРОТКИХ
}

\section{ЭЛЕКТРИЧЕСКИХ ИМПУЛЬСОВ НА НАНОСТРУКТУРИРОВАННЫЕ ЛИПОСОМАЛЬНЫЕ КАПСУЛЫ, НАХОДЯЩИЕСЯ В ВОДНОЙ ДИЭЛЕКТРИЧЕСКОЙ СРЕДЕ}

\author{
Ю. В. Гуляев ${ }^{1}$, В. А. Черепенин ${ }^{1}$, И. В. Таранов ${ }^{1}$, В. А. Вдовин ${ }^{1}$, Г. Б. Хомутов ${ }^{1,2}$ \\ ${ }^{1}$ Институт радиотехники и электроники им. В.А. Котельникова РАН, \\ 125009, Москва, ул. Моховая, 11, стр. 7 \\ ${ }^{2}$ Московский государственный университет им. М.В. Ломоносова, \\ 119992, Москва, Ленинские горы 1 , стр. 2 \\ Статья поступила в редакцию 26 октября 2018 г.
}

Аннотация. Впервые получены новые нанокомпозитные липосомы и везикулы с модифицированной структурой, содержащие функциональные неорганические электропроводящие наночастицы, связанные как с внутренней, так и с внешней поверхностью липосомальной мембраны. Изучено влияние ультракоротких импульсов электрического поля длительностью менее 10 нс и напряженностью в диэлектрической водной среде порядка 10 кВ/см на водную суспензию таких нанокомпозитных липосом, содержащих капсулированное модельное низкомолекулярное соединение $(\mathrm{NaCl})$. Было установлено, что в результате воздействия таких импульсов происходит декапсуляция и разрушение нанокомпозитных липосом, присутствующих в суспензии, сопровождающееся соответствующим увеличением проводимости суспензии. Показано, что чувствительность нанокомпозитных липосомальных капсул к электрическим воздействиям обусловлена включением в их структуру электропроводящих наночастиц. Обнаружено, что эффект декапсуляции липосомальных капсул значительно выше в случае воздействия импульсов электрического поля на липосомальные капсулы, связанные с наночастицами магнетита по сравнению со случаем аналогичного воздействия на те же капсулы, не содержащие проводящие наночастицы. Этот факт обусловливает избирательность воздействия электрических импульсов на нанокомпозитные мембранные везикулы, содержащие электропроводящие наночастицы. 
Проведен теоретический анализ нетеплового взаимодействия наноструктурированных липосомальных капсул, содержащих на внешней и внутренней поверхности мембраны проводящие наночастицы, с ультракороткими электрическими импульсами. Построена теоретическая модель нетеплового взаимодействия наноструктурированных липосомальных капсул с ультракороткими электрическими импульсами. В рассматриваемой модели электропроводящие наночастицы связаны с внешней и внутренней поверхностью мембран нанокомпозитных липосомальных капсул. В рамках построенной модели описаны механизмы разрушения липосомальной оболочки капсул, обусловленные взаимодействием проводящих сферических наночастиц, расположенных на противоположных поверхностях липосомальной мембраны, возникающим в результате ультракороткого электрического воздействия на водные суспензии наноструктурированных липосомальных капсул.

Ключевые слова: капсулы, липосомы, структура, наночастицы, полиэлектролиты, ультракороткие импульсы электрического поля.

Abstract. For the first time, new nanocomposite liposomes and vesicles with a modified structure containing functional inorganic electrically conductive nanoparticles associated with both the inner and the outer surface of the liposomal membrane were prepared. The effect of ultrashort electric field pulses with a duration of less than $10 \mathrm{~ns}$ and an intensity in a dielectric aqueous medium of the order of 10 $\mathrm{kV} / \mathrm{cm}$ on the aqueous suspension of such nanocomposite liposomes containing an encapsulated model low molecular weight compound $(\mathrm{NaCl})$ has been studied. It was found that as a result of exposure to such impulses, decapsulation and destruction of nanocomposite liposomes present in the suspension occurs, accompanied by a corresponding increase in the conductivity of the suspension. It is shown that the sensitivity of nanocomposite liposomal capsules to external electrical effects is due to the inclusion of electrically conductive nanoparticles in their structure. It was found that the effect of decapsulation of liposomal capsules is significantly higher in the case of the impact of electric field pulses on liposomal capsules with bound magnetite nanoparticles compared with the case of a similar effect on the same capsules that do 
not contain conducting nanoparticles. This fact determines the selectivity of the effect of electric pulses on nanocomposite membrane vesicles containing electrically conductive nanoparticles. A theoretical analysis of non-thermal interaction of nanostructured liposomal capsules containing conducting nanoparticles on the outer and inner surfaces of the membrane with ultrashort electrical pulses was carried out. A theoretical model of non-thermal interaction of nanostructured liposomal capsules with ultrashort electrical pulses is constructed. In the model under consideration, electrically conductive nanoparticles are associated with the outer and inner surfaces of membranes of nanocomposite liposomal capsules. Within the framework of the constructed model, the mechanisms of destruction of the liposomal capsule membrane are described, due to the interaction of conducting spherical nanoparticles located on opposite surfaces of the liposomal membrane resulting from the ultrashort electrical effect on aqueous suspensions of nanostructured liposomal capsules.

Keywords: capsules, liposomes, structure, nanoparticles, polyelectrolytes, ultrashort pulse of electric field.

\section{1. Введение}

В настоящее время активно разрабатываются нанокапсулы в качестве носителей лекарственных средств и ищутся методы управляемого высвобождения инкапсулированных веществ под действием внешних физических или химических воздействий. Открытие метода послойной полиионной сборки привело к появлению нового типа микроконтейнеров полых полиэлектролитных нанокомпозитных микрокапсул $[1,2]$, которые могут быть использованы для решения проблемы адресной доставки лекарственных веществ в организме человека. Обнаружено, что проницаемость оболочки таких микрокапсул может изменяться в зависимости от величины $\mathrm{pH}$ раствора [3, 4], а также под действием оптического излучения [5], переменного магнитного поля [6] и электромагнитного излучения в микроволновом диапазоне [7-9]. В тоже время трудоемкая многостадийная технология получения полиэлектролитных нанокомпозитных микрокапсул и 
капсулирования в них заданных веществ затрудняет использование этих капсул в медицинских приложениях.

Другой тип капсул, основанный на биомиметических объектах липосомах лишен вышеуказанных недостатков и уже активно используется в подходах к решению задачи адресной доставки лекарственных веществ в организме человека $[10,11]$ и других модельных биофизических исследованиях. Наиболее актуальной частью проблемы адресной доставки лекарственных веществ является решение задачи гарантированного дистанционного с одной стороны, и безопасного для биологической среды с другой, раскрытия капсулы и выделения инкапсулированного вещества. Выбор ультракороткого нетермического электрического воздействия в качестве метода декапсуляции специально синтезированных, чувствительных к данному типу воздействия, наноструктурированных липосомальных капсул, содержащих в оболочке неорганические наночастицы, оказывается весьма плодотворным подходом к решению проблемы избирательности воздействия на лекарственные капсулы [12, 13]. Уникальные свойства неорганических наночастиц открывают возможности для их применения в качестве важнейших функциональных компонентов перспективных технологий [14]. Так, например, функционирующий при комнатной температуре одноэлектронный туннельный транзистор впервые был создан с использованием металлических нанокластеров [15-18]. Металлические и магнитные наночастицы традиционно используются при диагностике, терапии и в нано биомедицинских исследованиях [19]. Обнаружено, что связанные с молекулой ДНК квазилинейные полупроводниковые наностержни CdSe обладают существенно поляризованным характером флюоресценции [17, 20].

В данной работе развивается подход к решению задачи избирательного электрического воздействия на транспортные лекарственные капсулы. Ультракороткие импульсы электрического поля с высокой напряженностью, не оказывающие при этом термического воздействия, использованы в качестве инструмента для вскрытия транспортных капсул, созданных специально для 
этого типа воздействия. Наноструктурированные липосомальные капсулы, связанные с наночастицами магнетита как внутренней, так и внешней поверхностью липосомальной мембраны, были специально созданы для увеличения чувствительности капсулы к выбранному типу воздействия.

\section{2. Создание нанокомпозитных липосомальных капсул с} модифицированной структурой

Стабильные водные суспензии коллоидных наночастиц магнетита и золота, имеющих диаметр менее 10 нм были получены по методу Массарта [21].

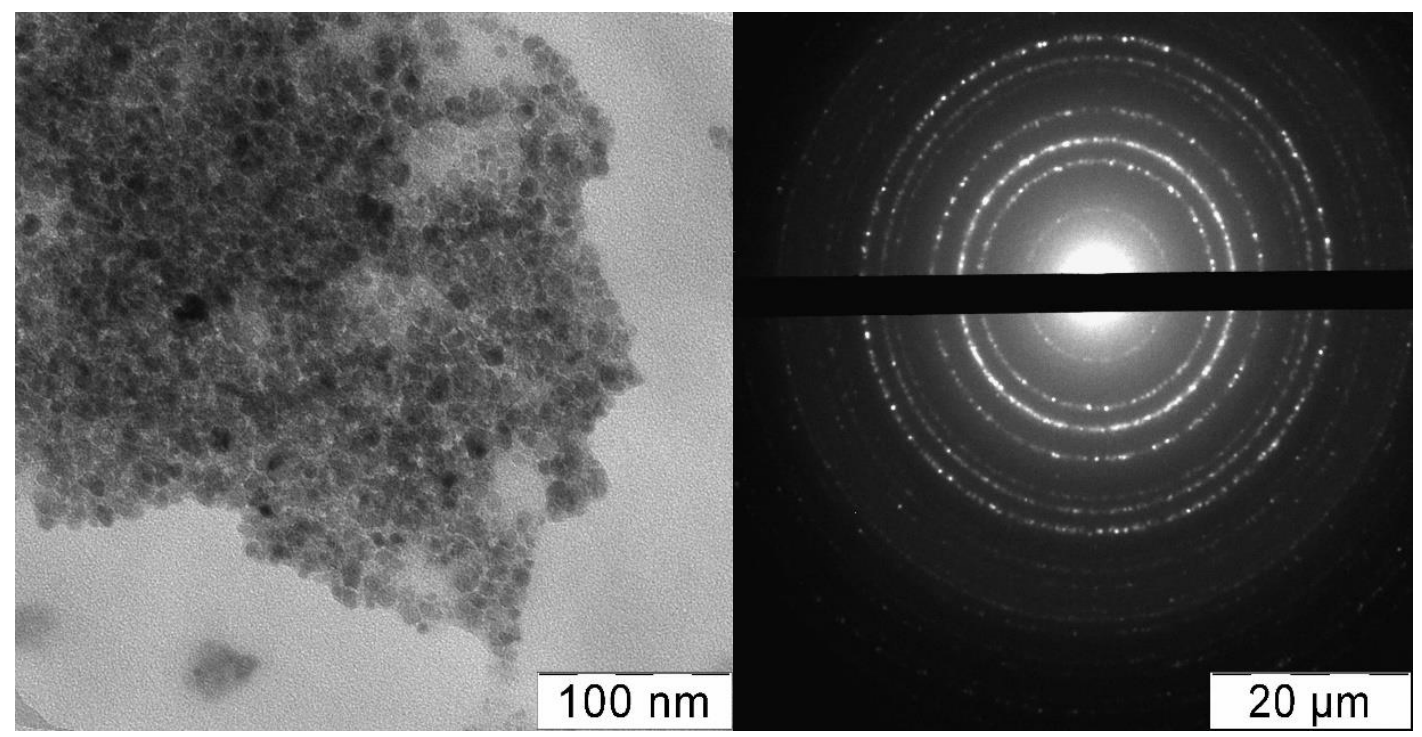

Рис. 1. Слева: характерное электронномикроскопическое изображение образца синтезированных наночастиц магнетита. Справа: картина электронной дифракции, полученная на данном образце наночастиц.

На Рис. 1 представлено характерное электронномикроскопическое изображение образца синтезированных наночастиц магнетита (слева). Справа на Рис. 1 представлена соответствующая электронограмма, основные дифракционные рефлексы которой полностью соответствуют стандартной электронограмме эталонного образца нанофазного магнетита.

Особое внимание было уделено получению суспензий квазимонодисперсных наночастиц, обеспечивающих достаточно высокую воспроизводимость их физико-химических свойств и, соответственно, характеристик нанокомпозитных липосом, содержащих такие наночастицы. 


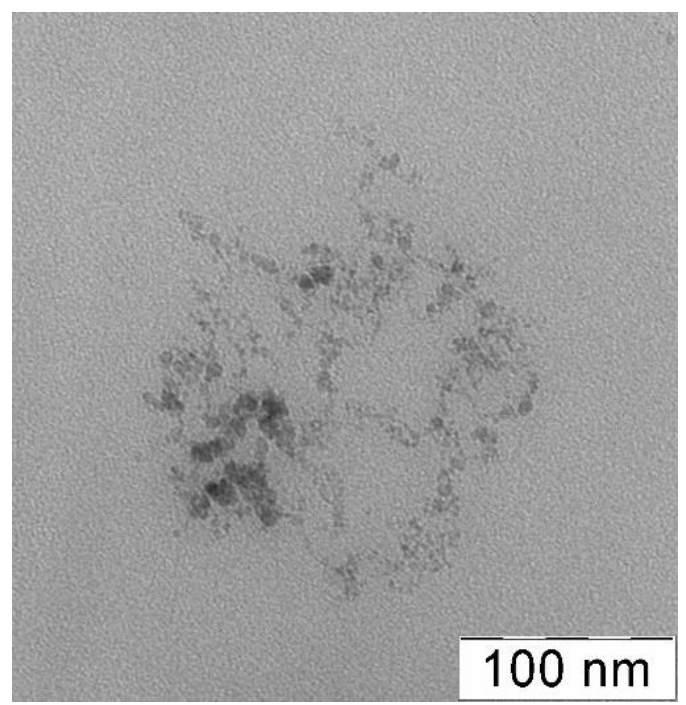

2.a.

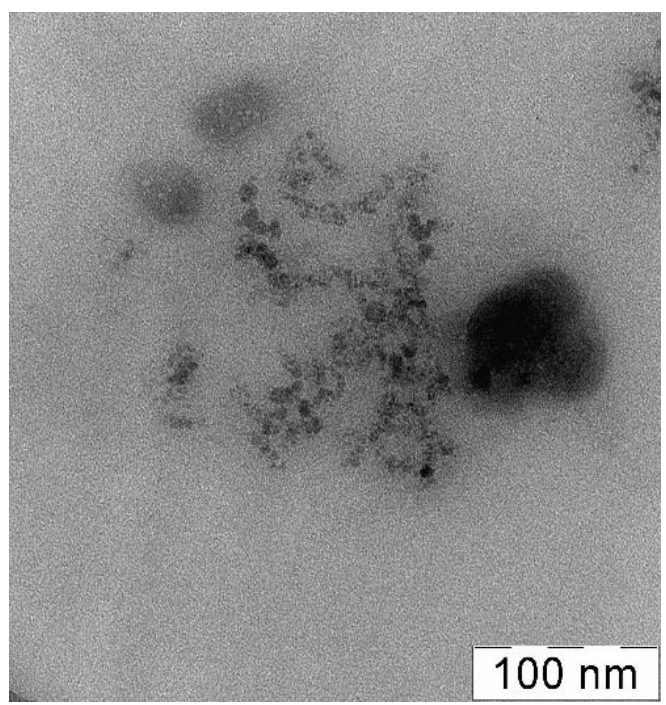

2.б.

Рис. 2. Изображения нанокомпозитных липосом с модифицированной структурой, содержащих наночастицы магнетита $\mathrm{Fe}_{3} \mathrm{O}_{4}$. На Рис. 2.а. липосома не содержала раствор $\mathrm{NaCl}$, а на Рис. 2.б. - содержала. Изображения получены методом просвечивающей электронной микроскопии.

Стеарилспермин был синтезирован из стеариновой кислоты $\left(\mathrm{C}_{17} \mathrm{H}_{35} \mathrm{COOH}\right)$ и природного полиамина спермина $\left(\mathrm{C}_{10} \mathrm{H}_{26} \mathrm{~N}_{4}\right)$ фирмы Sigma/Aldrich путем формирования между ними пептидной (амидной) связи. В настоящей работе синтезированы новые нанокомпозитные липосомы с модифицированной структурой, в которых функциональные неорганические наночастицы, связаны как с внутренней, так и с внешней поверхностью липосомальной мембраны. Идея создания таких липосом обусловлена стремлением увеличить чувствительность создаваемых нанокомпозитных везикул к внешнему воздействию ультракоротких электрических импульсов, что позволило бы снизить величины напряженности внешнего импульсного электрического поля, при которых будет происходить эффективное изменение структуры и проницаемости мембран таких липосом, приводящее к эффекту декапсуляции. Для создания таких нанокомпозитных везикул была разработана специальная оригинальная методика, отличающаяся от используемой нами ранее $[12,13]$ методики получения смешанных липосом тем, что в водный буферный раствор, который вводят в контакт с сухой смесью молекул 
фосфатидилхолина и стеароилспермина и подвергают воздействию ультразвука, изначально вводят коллоидные электропроводящие наночастицы. В работе установлена возможность формирования таких нанокомпозитных липосом, содержащих наночастицы магнетита $\mathrm{Fe}_{3} \mathrm{O}_{4}$, a также возможность капсулирования в таких липосомах низкомолекулярных соединений с целью их последующего высвобождения ультракороткими импульсами электрического поля высокой напряженности.

На Рис. 2 представлены характерные электронномикроскопические изображения нанокомпозитных липосом с модифицированной структурой, содержащих наночастицы магнетита как на внутренней, так и на внешней поверхности липосомальной мембраны.

3. Исследование влияния ультракоротких электрических импульсов на нанокомпозитные липосомы с модифицированной структурой

Возможность дистанционной декапсуляции вышеописанных нанокомпозитных липосомальных капсул, содержащие на внешней и внутренней поверхности мембраны сферические проводящие наночастицы, при воздействии на них ультракоротких электрических импульсов может быть исследована в рамках ранее использованной [12, 13] схемы эксперимента (Рис. 3.). Между плоскими электродами с зазором $L=1 \mathrm{~cm}$ находится трансформаторное масло с относительной диэлектрической проницаемостью $\varepsilon_{\mathrm{M}}=2.2$, в которое помещен цилиндрический контейнер диаметром $D=5$ мм с водной суспензией предварительно синтезированных нанокомпозитных липосомальных капсул. На плоские электроды подаются импульсы напряжения $U_{0}=1,510^{5}$ В длительностью $\tau=10^{-8} \mathrm{c}$.

Воздействие ультракоротких электрических импульсов на суспензию нанокомпозитных липосом с модифицированной структурой вызывало декапсуляцию липосомальных капсул, высвобождая при этом в окружающую воду, содержащуюся внутри липосомальных капсул, соль $\mathrm{NaCl}$. Регистрация изменения удельной проводимость водной суспензии нанокомпозитных липосом, обусловленного высвобождением $\mathrm{NaCl}$ из внутреннего 
липосомального объема в водную среду, позволяло судить о декапсуляции липосомальных капсул.

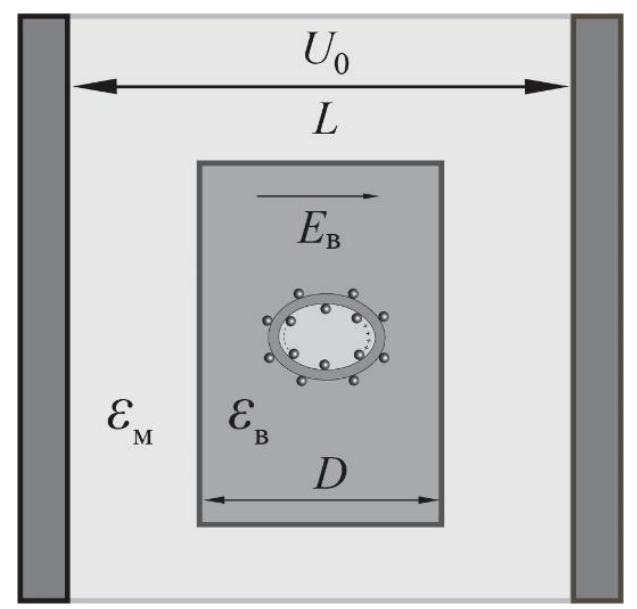

Рис. 3. Схема воздействия ультракоротких электрических импульсов на слабо проводящую водную суспензию наноструктурированных липосомальных капсул, содержащих на внешней и внутренней поверхности мембраны, проводящие наночастицы.

Таблица 1. - Результаты измерения проводимости суспензии нанокомпозитных мембранных везикул, содержащих наночастицы магнетита на внешней и внутренней поверхности мембраны, до и после воздействия импульсов электрического поля и детергента тритон X-100.

\begin{tabular}{|c|c|c|}
\hline & $\begin{array}{c}\text { Суспензия } \\
\text { мембранных } \\
\text { везикул }\end{array}$ & $\begin{array}{c}\text { Суспензия } \\
\text { мембранных } \\
\text { везикул } \\
+ \text { наночастицы } \\
\text { магнетита }\end{array}$ \\
\hline Проводимость исходной суспензии & $\mathbf{3 0 \pm 2}$ мкСм/см & $\mathbf{3 5} \pm \mathbf{2}$ мкС $/ \mathrm{cm}$ \\
\hline $\begin{array}{c}\text { Проводимость суспензии после } \\
\text { воздействия импульсов } \\
\text { электрического поля }\end{array}$ & $\mathbf{5 0 \pm 2}$ мкСм/см & $\mathbf{9 5} \pm \mathbf{3}$ мкСм/см \\
\hline $\begin{array}{c}\text { Проводимость суспензии после } \\
\text { добавления детергента тритона Х-100 }\end{array}$ & $\mathbf{9 0 \pm 2}$ мкСм/см & $\mathbf{9 8} \pm \mathbf{2}$ мкСм/см \\
\hline
\end{tabular}

Среднеквадратичная погрешность в таблице определена исходя из полученных данных серии аналогичных экспериментов. Если принять 
изменение значения проводимости образцов после разрушения везикул детергентом тритоном X-100 за $100 \%$, можно оценить в процентном соотношении долю вышедшего в наружный объем раствора соли $\mathrm{NaCl}$. Так, при воздействии электрическими импульсами на нанокомпозитные мембранные везикулы на основе липосом без наночастиц выход в наружный объем соли $\mathrm{NaCl}$ составил 33,3 \%. Тогда как, в случае с нанокомпозитными мембранными везикулами на основе липосом и наночастиц магнетита, выход в наружный объем соли $\mathrm{NaCl}$ после воздействия электрическими импульсами составил 95,2 \%. Данный результат свидетельствует о существенном увеличении чувствительности нанокомпозитных липосомальных капсул к электрическим воздействиям за счет включения в их структуру электропроводящих наночастиц. Полученные результаты свидетельствуют, что эффект нарушения целостности мембран липосом значительно меньше при воздействии импульсов электрического поля на мембранные везикулы, не содержащие проводящих наночастиц, по сравнению с аналогичным воздействием на нанокомпозитные мембранные везикулы, связанные с наночастицами магнетита. Этот факт обусловливает избирательность воздействия электрических импульсов на нанокомпозитные мембранные везикулы, содержащие электропроводящие наночастицы.

\section{4. Модель нетермического воздействия ультракоротких электрических} импульсов на наноструктурированные липосомальные капсулы с модифицированной структурой

Для изучения механизма нетеплового воздействия ультракоротких электрических импульсов на наноструктурированные липосомальные капсулы, содержащие на внешней и внутренней поверхности мембраны проводящие наночастицы, рассмотрим следующую модель. Основой нанокомпозитных липосомальных капсул являются однослойные липосомы, синтезированные из амфифильных соединений фосфатидилхолина - 80\% и стеарилспермина (СС) $20 \%$ с характерным размером около 200 нм. Внешняя и внутренняя поверхности липосомальной мембраны связаны с проводящими наночастицами 
магнетита с формой близкой к сферической и характерным размером 6 нм. Внутренний объем липосомальных капсул заполнен раствором соли $\mathrm{NaCl}$ и вследствие этого является проводящим. Построенный таким образом липосомальные капсулы находятся в водной среде с низкой удельной проводимостью. Длительность электрического импульса $\tau$ удовлетворяет условиям $\sigma_{\text {внеш }}^{-1} \gg \tau \gg \sigma_{\text {внут }}^{-1}$, где $\sigma_{\text {внеш, }}, \sigma_{\text {внут }}-$ удельные проводимости водных солевых растворов вне и внутри капсул. В этом случае внутреннюю область капсулы можно считать проводником, а внешнюю - диэлектриком.

Отметим, что для значений параметров нашей задачи выполняется условие квазистационарности электромагнитного поля $c \tau \gg l(c-$ скорость света) [22]. Длительность электрического импульса $\tau$ удовлетворяет условиям $\sigma_{\text {внеш }}^{-1} \gg \tau \gg \sigma_{\text {внут }}^{-1}$, где $\sigma_{\text {внеш, }}, \sigma_{\text {внут }}-$ удельные проводимости водных солевых растворов вне и внутри капсул, при котором внутреннюю область капсулы можно считать проводником, а внешнюю - диэлектриком. Оболочка капсулы является диэлектриком $\quad \mathrm{c}$ диэлектрической проницаемостью $\varepsilon_{Л}=2,7$. Молекулы СС в водной среде приобретают единичный положительный заряд $q$ равный по величине заряду электрона.

Ранее было показано [12], что при данной схеме воздействия (Рис. 3.) во время действия электрического импульса липосомальные капсулы оказывается во внешнем электрическом поле

$$
E_{\mathrm{B}}=\frac{2 \varepsilon_{\mathrm{M}}}{\varepsilon_{\mathrm{B}}+\varepsilon_{\mathrm{M}}-\left(\varepsilon_{\mathrm{B}}-\varepsilon_{\mathrm{M}}\right) \frac{D^{2}}{L^{2}}} \frac{U_{0}}{L}
$$

которое принимает значение $E_{\mathrm{B}}=10.5 \mathrm{\kappa B} / \mathrm{cm}$ в рассматриваемом случае $D / L=1 / 2, \varepsilon_{\mathrm{B}}=80$ - диэлектрическая проницаемость воды.

Во время действия электрического импульса такая наноструктурированная липосомальная капсула, окруженная водой, находится во внешнем однородном электрическом поле $E_{\mathrm{B}}$. Вследствие действия внешнего электрического поля форма липосомы может изменяться, сохраняя при этом постоянный объем. Как было показано ранее [12], форма липосомы 
изменяется от изначально сферической до формы вытянутого эллипсоида вращения с наибольшей полуосью параллельной внешнему полю $\vec{E}_{\mathrm{B}}$. Рассмотрим задачу о поляризации слоистой эллипсоидальной среды во внешнем однородном электрическом поле. Выберем эллипсоидальную систему координат с центром в центре липосомы и наибольшей полуосью параллельной $\vec{E}_{\mathrm{B}}$. В этом случае слоистая среда состоит из следующих 3-х областей (Рис. 4.).

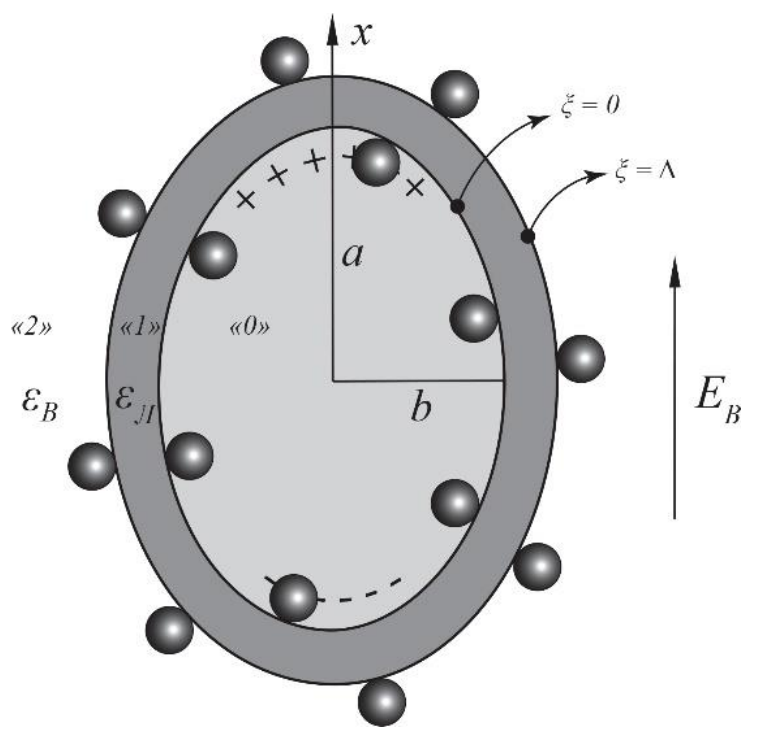

Рис. 4. Поляризация нанокомпозитной липосомы во внешнем электрическом поле.

Область «0» - внутренность вытянутого эллипсоида вращения: $-b^{2}<\xi<$ $0,-a^{2}<\zeta<-b^{2}, 0<\varphi<2 \pi$, где $(\xi, \zeta, \varphi)$ - эллипсоидальные координаты, $a>b=c$ - главные полуоси вытянутого эллипсоида вращения, является проводящей.

Область «1» - эллипсоидальный слой с диэлектрической проницаемостью $\varepsilon_{Л}: 0<\xi<\Delta,-a^{2}<\zeta<-b^{2}, 0<\varphi<2 \pi$.

Область «2»- внешность эллипсоида с диэлектрической проницаемостью $\varepsilon_{\mathrm{B}}: \Delta,<\xi, a^{2}<\zeta<-b^{2}, 0<\varphi<2 \pi$.

Электрический потенциал $\phi=\phi(\xi, \zeta)$ в рассматриваемом случае является решением уравнения Лапласа $\Delta \phi=0$, решение которого ищем в следующем виде: 


$$
\phi=\left\{\begin{array}{c}
\phi_{0}=0,-b^{2} \leq \xi \leq 0,-a^{2} \leq \zeta \leq-b^{2}, 0 \leq \varphi<2 \pi, \\
\phi_{\text {Л }}=E_{1} x K(\xi) / n, 0 \leq \xi \leq \Delta,-a^{2} \leq \zeta \leq-b^{2}, 0 \leq \varphi<2 \pi, \\
\phi_{\mathrm{B}}=E_{\mathrm{B}} x(1-A J(\xi) / n), \Delta \leq \xi, a^{2} \leq \zeta \leq-b^{2}, 0 \leq \varphi<2 \pi,
\end{array}\right.
$$

где $\quad J(\xi)=\frac{a b^{2}}{2} \int_{\xi}^{\infty} \frac{d \xi^{\prime}}{\left(\xi^{\prime}+a^{2}\right)^{3 / 2}\left(\xi^{\prime}+b^{2}\right)}, \quad K(\xi)=\frac{a b^{2}}{2} \int_{0}^{\xi} \frac{d \xi^{\prime}}{\left(\xi^{\prime}+a^{2}\right)^{3 / 2}\left(\xi^{\prime}+b^{2}\right)}, \quad n=$ $\frac{1-e^{2}}{e^{2}}\left(\frac{1}{2 e} \ln \frac{1+e}{1-e}-1\right) \quad$-коэффициент $\quad$ деполяризации, $\quad e=\sqrt{1-b^{2} / a^{2}} \quad-$ эксцентриситет, $\Delta=(a+d)^{2}-a^{2}$ - параметр толщины липосомальной мембраны, $d$ - толщина мембраны, $x= \pm \sqrt{\frac{\left(\xi+a^{2}\right)\left(\zeta+a^{2}\right)}{a^{2}-b^{2}}}$-декартова координата вдоль большей полуоси эллипсоида.

Граничные условия

$$
\phi_{\text {Л }}(\xi=\Delta)=\phi_{\mathrm{B}}(\xi=\Delta), \varepsilon_{\text {Л }} \frac{\partial \phi_{\text {Л }}}{\partial \xi}(\xi=\Delta)=\varepsilon_{\mathrm{B}} \frac{\partial \phi_{\mathrm{B}}}{\partial \xi}(\xi=\Delta)
$$

позволяют найти коэффициенты $A$ и $E_{1}$ в следующем виде:

$$
\left\{\begin{array}{c}
E_{1}=\frac{n \varepsilon_{\mathrm{B}}}{n \varepsilon_{Л}+(1-n)\left(\varepsilon_{\mathrm{B}}-\varepsilon_{Л}\right) \frac{\Delta}{2 a^{2}}} E_{\mathrm{B}} \\
A=\frac{n\left(\varepsilon_{Л}-\frac{\Delta}{2 a^{2}}\left(\varepsilon_{\mathrm{B}}-\varepsilon_{Л}\right)\right)}{n \varepsilon_{Л}+(1-n)\left(\varepsilon_{\mathrm{B}}-\varepsilon_{Л}\right) \frac{\Delta}{2 a^{2}}}
\end{array}\right.
$$

Напряженность электрического поля вблизи полярной области $\left(\zeta=-b^{2}\right)$ вытянутой липосомальной капсулы в этом случае принимает вид

$$
E_{\text {Л }}=\frac{n \varepsilon_{\mathrm{B}}}{n \varepsilon_{Л}+(1-n)\left(\varepsilon_{\mathrm{B}}-\varepsilon_{Л}\right) \frac{\Delta}{2 a^{2}}} \frac{E_{\mathrm{B}}}{n} .
$$

Поляризация внутренней проводящей области липосомальной капсулы приводит к появлению поверхностной плотности заряда

$$
\sigma_{Q}=\sigma_{Q}(\zeta)=\frac{\varepsilon_{Л} b}{4 \pi a e n} \sqrt{\frac{\zeta+a^{2}}{-\zeta}} E_{1}
$$

на внутренней поверхности липосомальной мембраны. Это приводит к тому, что у сферических проводящих наночастиц, находящихся на внешней поверхности липосомальной мембраны, возникают заряды, которые могут быть 
найдены методом изображений [22]. Дипольный момент «изображения», возникающий у наночастицы, расположенной в полярной области, индуцируемый поверхностным зарядом $\sigma_{Q}$, можно определить следующим образом:

$$
\mu_{Q}=\int x^{\prime} d Q^{\prime},
$$

где $x^{\prime}=\frac{r^{2}}{l^{2}}(a+r-x), d Q^{\prime}=\frac{r}{l} \sigma_{Q}(\zeta) d S, l^{2}=a^{2} e^{2}\left[\left(\frac{1+\gamma}{e^{2}}-u\right)^{2}-\left(\frac{1+\gamma}{e^{2}}-1\right)^{2}+\right.$ $\left.\frac{\gamma^{2}}{e^{2}}\right], d S=\frac{2 \pi b}{a e} \sqrt{\frac{-\zeta}{\zeta+a^{2}}} d \zeta, u=\frac{\sqrt{\zeta+a^{2}}}{a e}, \gamma=\frac{r}{a}, r$ - радиус наночастицы.

В этом случае дипольный момент «изображения» можно представить в виде интеграла

$$
\mu_{Q}=\frac{r^{3} \varepsilon_{Л}\left(1-e^{2}\right) E_{1}}{n e^{3}} \int_{-1}^{1} \frac{(1+\gamma-u) u}{\left[\left(\frac{1+\gamma}{e^{2}}-u\right)^{2}-\left(\frac{1+\gamma}{e^{2}}-1\right)^{2}+\frac{\gamma^{2}}{e^{2}}\right]^{3 / 2}} d u,
$$

который для слабо вытянутой липосомы $(e \rightarrow 0)$ принимает вид

$$
\begin{aligned}
& \mu_{Q}=\frac{3}{2} \frac{\varepsilon_{Л} r^{2} R E_{1}}{1+\gamma}\left[\delta\left(1+\beta^{2}\right)-\frac{\delta \beta\left(1+\beta^{2}\right)}{\sqrt{2+\beta^{2}}}+\beta\left(\frac{\gamma}{2(1+\gamma)}+\beta^{2}\right)\left(\sqrt{2+\beta^{2}}-\beta\right)-\right. \\
& \left.-\frac{2}{3} \beta\left(\left(2+\beta^{2}\right)^{\frac{2}{3}}-\beta^{3}\right)\right]
\end{aligned}
$$

где $\beta=\frac{1}{\sqrt{2}} \frac{\gamma}{\sqrt{1+\gamma}}, \delta=1-\frac{\gamma}{2(1+\gamma)}, \gamma=\frac{r}{R}, R-$ радиус шара с объемом, равным объему липосомы.

Поскольку молекулы СС в водной среде приобретают единичный положительный заряд $q$ равный по величине заряду электрона, липосомальная поверхность равномерна заряжена с постоянной плотностью заряда $\sigma_{C}=q / S_{C}$, где $S_{C}$ - площадь, приходящаяся на одну молекулу СС. Этот поверхностный заряд $\sigma_{C}$ создает дополнительный дипольный момент «изображения»

$$
\mu_{C}=\frac{4 \pi r^{3} b \sigma_{C}}{a e^{3}} \int_{-1}^{1} \frac{(1+\gamma-u) \sqrt{1-e^{2} u}}{\left[\left(\frac{1+\gamma}{e^{2}}-u\right)^{2}-\left(\frac{1+\gamma}{e^{2}}-1\right)^{2}+\frac{\gamma^{2}}{e^{2}}\right]^{3 / 2}} d u
$$


у наночастицы, расположенной на внешней поверхности липосомальной мембраны вблизи полярной области. В случае слабо вытянутой липосомы $(e \rightarrow 0)$ этот дипольный момент «изображения» принимает вид

$$
\mu_{\mathrm{C}}=\frac{2 \pi r^{2} R \sigma_{C}}{1+\gamma}\left[\delta\left(1-\frac{\beta}{\sqrt{2+\beta^{2}}}\right)+\beta\left(\sqrt{2+\beta^{2}}-\beta\right)\right]
$$

В тоже время наночастицы, находящиеся на внутренней поверхности липосомальной $\quad$ мембраны, обладают $\quad$ зарядом $Q(\zeta)=4 \pi r^{2} \sigma_{Q}(\zeta) . \quad$ При достаточно высокой энергии взаимодействия двух наночастиц, расположенных на противоположных поверхностях липосомальной мембраны

$$
U_{E}=\frac{Q\left(\mu_{\mathrm{C}}+\mu_{Q}\right)}{\varepsilon_{\Omega} D^{2}}
$$

где $D$ - расстояние между центрами наночастиц, возможно разрушение липосомальной мембраны. Условием такого разрушения липосомальной мембраны является следующее

$$
U_{E}=U_{\Pi},
$$

где $U_{\Pi}=\pi r^{2} \alpha-$ доля поверхностной энергии липосомальной мембраны, приходящейся на одну наночастицу, $\alpha$ - коэффициент поверхностного натяжения липосомальной мембраны. Подставляя выражения (9) и (11) в условие (13), находим выражение для критического значения напряженности электрического поля вблизи липосомы,

$$
E_{\mathrm{B}}^{(\text {кр })}=\frac{\varepsilon_{\text {Л }}+\left(\varepsilon_{\mathrm{B}}-\varepsilon_{Л}\right) \frac{2 d}{R}}{\varepsilon_{\mathrm{B}}} \frac{\alpha D^{2}(1+\gamma)}{6 r^{2} R \sigma_{C}}\left[\delta\left(1-\frac{\beta}{\sqrt{2+\beta^{2}}}\right)+\beta\left(\sqrt{2+\beta^{2}}-\beta\right)\right]^{-1},
$$

приводящее к разрушению липосомальной мембраны двумя наночастицами, расположенными на противоположных поверхностях липосомальной мембраны. В рассматриваемом случае $S_{C}=150 \AA^{2}, \varepsilon_{Л}=2.7, \varepsilon_{\mathrm{B}}=80, \alpha=$ 25 дин/см [4], $R=100$ нм, $r=3$ нм, $D / r=3$, критическое значение напряженности электрического поля (14) становится равным 


$$
E_{\mathrm{B}}^{(\kappa р)}=3.3 \kappa \mathrm{B} / \mathrm{cm}
$$

и оказывается меньшим значения напряженности электрического поля $E_{\mathrm{B}}^{(e x)}=10.5$ кВ/см, возникавшего вблизи липосомальных капсул во время воздействия на них ультракоротких электрических импульсов в ранее проведенных экспериментах $[12,13]$. Следует отметить, что величина критического значения напряженности электрического поля (14), обусловленная взаимодействием наночастиц, расположенных на противоположных поверхностях липосомальной мембраны, оказывается меньше ранее найденной $[12,13]$ величины критического значения напряженности поля для случая липосомальных капсул, содержащих наночастицы только на внешней липосомальной поверхности.

\section{5. Заключение}

Впервые получены новые нанокомпозитные липосомы и везикулы с модифицированной структурой, содержащие функциональные неорганические электропроводящие наночастицы, связанные как с внутренней, так и с внешней поверхностью липосомальной мембраны. Изучено влияние ультракоротких импульсов электрического поля длительностью менее 10 нс и напряженностью в диэлектрической водной среде порядка 10 кВ/см на водную суспензию таких нанокомпозитных липосом, содержащих капсулированное модельное низкомолекулярное соединение $(\mathrm{NaCl})$. Было установлено, что в результате воздействия таких импульсов происходит декапсуляция и разрушение нанокомпозитных липосом, присутствующих в суспензии, сопровождающееся соответствующим увеличением проводимости суспензии. Показано, что чувствительность нанокомпозитных липосомальных капсул к электрическим воздействиям обусловлена включением в их структуру электропроводящих наночастиц. Обнаружено, что эффект декапсуляции липосомальных капсул значительно выше в случае воздействия импульсов электрического поля на липосомальные капсулы, связанные с наночастицами магнетита по сравнению со случаем аналогичного воздействия на те же капсулы, не содержащие 
проводящие наночастицы. Этот факт обусловливает избирательность воздействия электрических импульсов на нанокомпозитные мембранные везикулы, содержащие электропроводящие наночастицы.

Проведен теоретический анализ нетеплового взаимодействия наноструктурированных липосомальных капсул, содержащих на внешней и внутренней поверхности мембраны проводящие наночастицы, с ультракороткими электрическими импульсами. Построена теоретическая модель нетеплового взаимодействия наноструктурированных липосомальных капсул с ультракороткими электрическими импульсами. В рассматриваемой модели электропроводящие наночастицы связаны с внешней и внутренней поверхностью мембран нанокомпозитных липосомальных капсул. В рамках построенной модели описаны механизмы разрушения липосомальной оболочки капсул, обусловленные взаимодействием проводящих сферических наночастиц, расположенных на противоположных поверхностях липосомальной мембраны, возникающим в результате ультракороткого электрического воздействия на водные суспензии наноструктурированных липосомальных капсул.

Работа выполнена при поддержке Российского фонда фундаментальных исследований (РФФИ), проект № 18-29-02080.

\section{Литература}

1. Donath E., Sukhorukov G.B., Caruso F., Devis S.A., Möhwald H. Novel Hollow Polymer Shells by Colloid-Templated Assembly of Polyelectrolytes. Angew Chem. Int. Ed. Engl., 1998, Vol. 37, p. 2202.

2. Sukhorukov G.B., Donath E., Davis S.A., Lichtenfeld A., Caruso F., Popov V.I., Möhwald H. Stepwise polyelectrolyte assembly on particle surfaces: A Novel Approach to Colloid Design. Polym. Adv. Technol., 1998, Vol. 9, p. 759.

3. Sukhorukov G.B., Antipov A., Voigt A., Donath E., Möhwald H. pH-Controlled Macromolecule Encapsulation in and Release from Polyelectrolyte Multilayer Nanocapsules. Macromol. Rapid Commun, 2001, Vol. 22, pp. 44-46. 
4. Gennady B. Khomutov, Vitaly P. Kim, Kirill V. Potapenkov, Alexander A. Parshintsev, Eugene S. Soldatov, Nazym N. Usmanov, Alexander M. Saletsky, Andrey V. Sybachin, Alexander A. Yaroslavov, Vasiliy A. Migulin, Igor V. Taranov, Vladimir A. Cherepenin, Yury V. Gulyaev, Langmuir monolayers and Langmuir-Blodgett films of $\mathrm{pH}$-sensitive lipid. Colloids and Surfaces A: Physicochemical and Engineering Aspects, 2017, Vol. 532, pp. 150-154.

5. Radt B., Smith T.A., Caruso F. Optically Addressable Nanostructured Capsules. Adv. Mater, 2004, vol. 16, pp. 2184-2189.

6. Lu Z., Prouty M.D., Guo Z., Golub V.O., Kumar C.S.S.R., Lvov Y.M. Magnetic switch of permeability for polyelectrolyte microcapsules embedded with $\mathrm{Co}, \mathrm{Au}$ nanoparticles. Langmuir, 2005, Vol. 21, pp. 2042-2050.

7. D. A. Gorin, D. G. Shchukin, A. I. Mikhailov, K. Köhler, S. A. Sergeev, S. A. Portnov, I. V. Taranov, V. V. Kislov, G. B. Sukhorukov. Effect of Microwave Radiation on Polymer Microcapsules Containing Inorganic Nanoparticles. Technical Physics Letters, 2006, Vol. 32, No. 1, pp. 70-72.

8. Gorin D.A., Shchukin D.G., Koksharov Yu.A., Portnov S.A., Köhler K., Taranov I.V., Kislov V.V., Khomutov G.B., Möhwald H., Sukhorukov G.B. Effect of microwave irradiation on composite iron oxide nanoparticle/polymer microcapsules. Progress in Biomedical Optics and Imaging. 2007. Vol. 6536, p. 653604.

9. Gulyaev Y.V., Cherepenin V.A., Vdovin V.A., Taranov I.V., Sukhorukov G.B., Gorin D.A., Khomutov G.B. Decapsulation of polyelectrolyte nanocomposite microcapsules by pulsed microwave effect. Journal of Communications Technology and Electronics, 2015. Vol. 60, No. 11, pp. 1286-1290.

10. Schwendener R.A. Bio-Applications of Nanoparticles. Edited by Chan W.C.W. Ser. Advances in Experimental Medicine and Biology, 2007, Vol. 620, p. 117.

11. Amstad E., Kohlbrecher J., Muller E., Schweizer T., Textor M., Reimhult E. Triggered Release from Liposomes through Magnetic Actuation of Iron Oxide Nanoparticle Containing Membranes. Nano Letters, 2011, Vol. 11, pp. 16641670. 
12. Yu. V. Gulyaev, V. A. Cherepenin, I. V. Taranov, V. A. Vdovin, A. A. Yaroslavov, V. P. Kim, G. B. Khomutov. Remote decapsulation of nanocomposite liposomal capsules containing gold nanorods by ultrashort electric pulses. Journal of Communications Technology and Electronics, 2016, Vol. 61, No. , pp. 56-60.

13. Gulyaev Y.V., Cherepenin V.A., Vdovin V.A., Taranov I.V., Khomutov G.B., Yaroslavov A.A., Kim V.P. Pulsed electric field-induced remote decapsulation of nanocomposite liposomes with implanted conducting nanoparticles. Journal of Communications Technology and Electronics. 2015. T. 60. № 10. C. 10971108.

14. G. B. Khomutov, V P. Kim, Y A., Koksharov, K V. Potapenkov, A A. Parshintsev, E S. Soldatov, N N. Usmanov, A M., S, A V. Sybachin, A A. Yaroslavov, I V. Taranov, V A. Cherepenin, Y V. Gulyaev. Nanocomposite biomimetic vesicles based on interfacial complexes of polyelectrolytes and colloid magnetic nanoparticles. Colloids and Surfaces A: Physicochemical and Engineering Aspects, 2017, Vol. 532, 5 November, pp. 26-35.

15. Gubin S.P., Gulyaev Yu.V., Khomutov G.B., Kislov V, V., Kolesov V, V., Soldatov, E.S., Sulaimankulov, K.S., Trifonov, A.S. Molecular clusters as building blocks for nanoelectronics: The first demonstration of a cluster singleelectron tunnelling transistor at room temperature. Nanotechnology. 2002, Vol. 13, No. 2, pp.185.

16. Kislov V.V., Kolesov V.V., Taranov I.V. Electron transport through a molecular nanocluster. Journal of Communications Technology and Electronics, 2002, Vol. 47, No. 11, pp. 1266-1270.

17. Yu.V. Gulyaev, V.Kislov, V.V.Kolesov, I.V.Taranov, S.P.Gubin, G.B.Khomutov, E.S.Soldatov, I.A.Maximov, L.Samuelson. Electronics of Molecular Nanoclusters. International Journal of Nanoscience, 2004, Vol. 3, No. 1-2 pp. 137-147. 
18. Kislov V., Medvedev B., Gulyaev Yu., I. Taranov and V. Kashin. Organized superstructures at nanoscale and new functional nanomaterials. International Journal of Nanoscience. 2007, Vol. 6, No. 5, pp. 373.

19. Koning G.A., Eggermont A.M.M., Lindner L.H., ten Hagen T.L.M. Pharmaceutical Research, 2010, Vol. 27, No. 8, pp. 1750.

20. Artemyev M., Kisiel D., Abmiotko S. M. N. Antipina, G. B. Khomutov, V.V. Kislov, A.A. Rakhnyanskaya. Self-Organized, Highly Luminescent CdSe Nanorod-DNA Complexes. Journal American Chemical Society, 2004, Vol. 126, No. 34, pp. 10594.

21. Massart R. Preparation of aqueous magnetic liquids in alkaline and acidic media. IEEE Transactions on Magnetics, 1981, Vol. 17, pp. 1247-1248.

22. L. D. Landau, E. M. Livshits, Electrodynamics of Continuous Media. Pergamon, Oxford, 1984.

23. V. P. Kim, A. V. Ermakov, E. G. Glukhovskoy, A. A. Rakhnyanskaya, Yu. V. Gulyaev, V. A. Cherepenin, I. V. Taranov, P. A. Kormakova, K. V. Potapenkov, N. N. Usmanov, A. M. Saletsky, Yu. A. Koksharov, G. B. Khomutov. Planar Nanosystems on the Basis of Complexes Formed by Amphiphilic Polyamine, Magnetite Nanoparticles, and DNA Molecules Nanotechnologies in Russia, 2014, Vol. 9, No. 5-6, pp. 280-287.

\section{Для цитирования:}

Ю. В. Гуляев, В. А. Черепенин, И. В. Таранов, В. А. Вдовин, Г. Б. Хомутов. Нетермическое воздействие ультракоротких электрических импульсов на наноструктурированные липосомальные капсулы, находящиеся в водной диэлектрической среде. Журнал радиоэлектроники [электронный журнал]. 2018. № 11. Режим доступа: http://jre.cplire.ru/jre/nov18/3/text.pdf

DOI 10.30898/1684-1719.2018.11.3 